\title{
Effect of Functionally-Graded Calcium Titanate Film, Prepared by Metal-Organic Chemical Vapor Deposition, on Titanium Implant
}

\author{
Naru Shiraishi ${ }^{1,2, *}$, Risa Ishiko-Uzuka ${ }^{3}$, Kenta Takahashi $^{1}$, Toru Ogawa ${ }^{1}$, Takahisa Anada ${ }^{4}$, \\ Osamu Suzuki ${ }^{5}$, Takashi Goto ${ }^{6}$ and Keiichi Sasaki ${ }^{1}$ \\ 1 Division of Advanced Prosthetic Dentistry, Tohoku University Graduate School of Dentistry, Tohoku \\ University, 4-1 Seiryo-machi Aoba-ku, Sendai 980-8575, Japan; kenta@dent.tohoku.ac.jp (K.T.); \\ ogat-thk@umin.ac.jp (T.O.); keiichi.sasaki.e6@tohoku.ac.jp (K.S.) \\ 2 Division of Dysphagia Rehabilitation, Niigata University Graduate School of Medical and Dental Sciences, \\ Niigata University, 2-5274, Gakkocho-dori, Chuo-ku, Niigata 951-8514, Japan \\ 3 Division of Preventive Dentistry, Tohoku University Graduate School of Dentistry, Tohoku University, 4-1 \\ Seiryo-machi Aoba-ku, Sendai 980-8575, Japan; risa.ishiko.e4@tohoku.ac.jp \\ 4 Institute for Materials Chemistry and Engineering, Kyushu University, CE41 744 Motooka, Nishi-ku, \\ Fukuoka 819-0395, Japan; takahisa_anada@ms.ifoc.kyushu-u.ac.jp \\ 5 Division of Craniofacial Function Engineering, Tohoku University Graduate School of Dentistry, Tohoku \\ University, 4-1 Seiryo-machi Aoba-ku, Sendai 980-8575, Japan; suzuki-o@m.tohoku.ac.jp \\ 6 Division of Multi-Functional Materials, Institute for Materials Research, Tohoku University, 2-2-1 Katahira \\ Aoba-ku, Sendai 980-8577, Japan; goto@imr.tohoku.ac.jp \\ * Correspondence: nshiraishi@dent.tohokuniigata-u.ac.jp; Tel.: +81-22-717-8369
}

Received: 7 December 2018; Accepted: 27 December 2018; Published: 4 January 2019

\begin{abstract}
Calcium Titanate $\left(\mathrm{CaTiO}_{3}\right)$ has been introduced as an attractive biomaterial for the enhancement of calcium phosphate deposition in vivo and in vitro. We hypothesized that $\mathrm{CaTiO}_{3}$ directly coated on titanium (Ti) by metal-organic chemical vapor deposition (MOCVD) could be a suitable candidate for biocompatible coatings for medical devices, particularly dental implants. To prove this hypothesis, surface characterization, cell culture, and animal study were completed in this study. The result of this study showed that $\mathrm{CTO} 800$, a $\mathrm{CaTiO}_{3}$ film prepared by heating at $800{ }^{\circ} \mathrm{C}$, had a high hydrophilic surface. Mouse bone marrow stromal ST-2 cells cultured on substrates and CTO 800 exhibited cell differentiation, represented by alkaline phosphatase activity, compared with cells cultured on non-coated $\mathrm{Ti}$ and $\mathrm{CTO} 700\left(\mathrm{a} \mathrm{CaTiO}_{3}\right.$ film prepared by heating at $\left.700{ }^{\circ} \mathrm{C}\right)$. The push-in test value of CTO 800, a parameter that indicates the degree of osseointegration, was significantly higher than that of Ti. Calcium titanate coated on Ti by MOCVD has the potential to accelerate the process of osseointegration; thus, our results support the use of $\mathrm{CaTiO}_{3}$ coating for biocompatible biomaterial for medical applications, particularly dental implants.
\end{abstract}

Keywords: calcium titanate; metal-organic chemical vapor deposition; dental implant

\section{Introduction}

Ceramic coatings for metallic medical devices have been developed to provide a bioactive interface between artificial material and the body. Notably, these bioceramics are widely applied in orthopedic and dental applications [1,2]. The effects of such ceramic coatings and their roles in osseointegration have been described by Rahbek et al. [3] and Cunningham et al. [4]. Initially, reduction in local $\mathrm{pH}$ leads to partial dissolution of the calcium phosphate $(\mathrm{CaP})$ coating, thereby releasing its constituents into their respective ionic forms. The ions reprecipitate and incorporate into apatite crystals and collagen matrix structure. The 
increased concentrations of calcium and phosphate ions stimulate chemotaxis. Many compounds are used to generate ceramic coatings including hydroxyapatite (HA), $\mathrm{CaP}$, tricalcium phosphate (TCP), and calcium titanate $\left(\mathrm{CaTiO}_{3}\right)$; various methods are used, such as sputtering, laser methods, and sol-gel [5-9]. Among the available compounds, $\mathrm{CaTiO}_{3}$ has been identified as an attractive biomaterial for the enhancement of $\mathrm{HA}$ adhesion to metal implants. Webster et al. [10] reported that $\mathrm{CaTiO}_{3}$, formed by the annealing heat treatment as a result of interactions between $\mathrm{HA}$ and titanium (Ti) disk accelerated osteoblast adhesion, compared with either pure $\mathrm{HA}$ or $\mathrm{Ti}$. It has been reported that coating with $\mathrm{CaTiO}_{3}$ by sputtering or ion-beam-assisted deposition (IBAD) releases calcium ions in fetal bovine serum (FBS); in addition, phosphate is strongly adsorbed in experiments with $\mathrm{CaTiO}_{3}$ powder. Furthermore, HA and/or octacalcium phosphate (OCP) formation was identified on the surface of $\mathrm{CaTiO}_{3}$ films that were prepared by metal-organic chemical vapor deposition (MOCVD) after immersion in Hank's solution [11-13]. Our hypothesis is that $\mathrm{CaTiO}_{3}$ directly coated on Ti by MOCVD could be a suitable candidate for use as a biocompatible coating for medical devices, particularly dental implants. The aim of this study is to evaluate the biomechanical behavior, biocompatibility, and bioactivity of the $\mathrm{CaTiO}_{3}$ coated implant.

\section{Materials and Methods}

\subsection{Specimen Design}

Commercially pure titanium Grade 2 (Ti) was used as substrate material. Square disks (10.0 mm per side) and cylindrical non-screwed implants $(\varphi 1.0 \times 2.0 \mathrm{~mm})$ were prepared for the in vitro and in vivo tests (Figure 1). Each specimen was polished with wet abrasive paper (\#1500, Japanese Industrial Standards, Sankyo-Rikagaku Co, Saitama, Japan). These samples were washed with a surfactant, followed by ultrapure water; both were used in an ultrasonic cleaner for $5 \mathrm{~min}$, and samples were then dried at room temperature. $\mathrm{CaTiO}_{3}$ films were prepared by MOCVD using $\mathrm{Ca}(\mathrm{dpm})_{2}$ (bisdipivaloylmethanato-calcium) and $\mathrm{Ti}(\mathrm{O}-\mathrm{i}-\mathrm{Pr})_{2}(\mathrm{dpm})_{2}$ (bisisopropoxy-bisdipivaloylmethanato-titanium) precursors as reported in Reference [14]. Briefly, a vertical cold-wall type chemical vapor deposition (CVD) apparatus was employed to prepare $\mathrm{CaTiO}_{3}$ films. The source vapors which generated from headed these two source precursor powders were carried into the CVD reactor with Ar gas. $\mathrm{O}_{2}$ gas was separately introduced and mixed with the precursor vapors above a substrate holder. The total pressure in the CVD reactor was kept at $0.8 \mathrm{kPa}$, and the substrate temperature was changed from 700 to $800^{\circ} \mathrm{C}$. We designed two types of $\mathrm{CaTiO}_{3}$ films on Ti surfaces, dependent on the deposition condition of the heating temperature of the substrates, $700{ }^{\circ} \mathrm{C}$ and $800{ }^{\circ} \mathrm{C}$ for the in vitro test (CTO 700 and CTO 800) (Figure 1). Following the in vitro test, only one candidate that showed significant difference in alkaline phosphatase (ALP) activity compared with Ti was evaluated by the in vivo test. All samples underwent 15-W UV irradiation (UV cross linker FS-1500, Funakoshi, Japan) at a wavelength of $254 \mathrm{~nm}$ for $2 \mathrm{~h}$ before the experiments.
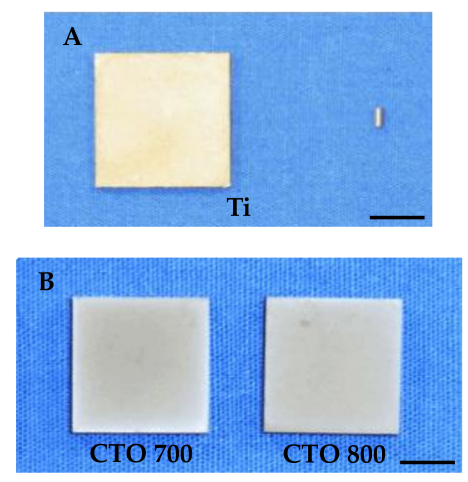

Figure 1. Specimen design for the in vitro and in vivo tests. (A) Square disks (10.0 $\mathrm{mm}$ per side) and cylindrical non-screwed implants $(\varphi 1.0 \times 2.0 \mathrm{~mm})$, made of $\mathrm{cpTi}$; these were used for the in vitro and in vivo tests, respectively. (B) Square disks of CTO 700 (left) and CTO 800 (right). Bars = $4 \mathrm{~mm}$. 


\subsection{Surface Characterization}

The surfaces of the specimens ( $\mathrm{Ti}, \mathrm{CTO} 700$, and CTO 800) were characterized precisely by the following techniques. Surface micromorphology was observed using scanning electron microscopy (SEM) (JSM-6500F, JEOL, Tokyo, Japan); elemental composition was examined by energy-dispersive X-ray (EDX) spectroscopy (JSM-6500F, JEOL). The surface roughness was calculated by a three-dimensional non-contact surface roughness tester (Talysurf CCI6000, Taylor Hobson, Leicester, UK) and a Gaussian filter was performed with the cut-off length of $50 \times 50 \mu \mathrm{m}$. Hydrophilicity was defined on the basis of the contact angle of a $1 \mu \mathrm{L} \mathrm{H}_{2} \mathrm{O}$ droplet onto the test surfaces, measured by portable contact angle meter (PCA-1, KYOWA, Saitama, Japan).

\subsection{Cell Culture on the Substrates}

Mouse bone marrow stromal ST-2 (ST-2) cells were used in this study (RIKEN Cell Bank; Tsukuba Science City, Ibaraki, Japan). The substrates were placed in ultra-low attachment surface 24-well plates (Sigma-Aldrich, St. Louis, MO, USA). A total of $1 \times 10^{4}$ ST-2 cells were seeded onto CTO 700 and CTO 800 square disks, with Ti as control, and incubated at $37{ }^{\circ} \mathrm{C}$ under $5 \% \mathrm{CO}_{2}$. Following $3 \mathrm{~h}$ cultured, the supernatant was removed and exchanged with fresh medium. The nutrient medium was composed of $\alpha$-minimal essential medium eagle ( $\alpha$ MEM; Sigma-Aldrich, St. Louis, MO, USA) containing 1\% penicillin/streptomycin (Invitrogen-Gibco, Carlsbad, CA, USA) and 10\% FBS (Life Technologies, Carlsbad, CA, USA).

\subsubsection{Cell Proliferation Assay}

The proliferation of cells on disks incubated for 7 and 14 days was quantified by WST- 8 colorimetric methods (Cell Counting Kit-8; Dojindo Laboratories, Kumamoto, Japan). During incubation, the culture medium was exchanged with fresh medium every 3 days. The proliferation of cells on the substrates was determined by the measurement of living cells using the WST- 8 assay.

\subsubsection{ALP Activity Measurement}

Alkaline phosphatase activity was estimated by a colorimetric assay using $p$-nitrophenylphosphate as the substrate (LabAssay ALP; Wako Pure Chemical, Osaka, Japan). Briefly, on days 7 and 14 of culture, cells were lysed in a nonionic surfactant (Triton X-100; Thermo Fisher Scientific, Waltham, MA, USA) and sonicated. The cell lysates were collected, and the ALP activity was determined using the reaction of $p$-nitrophenol conversion to $p$-nitrophenylate at $37^{\circ} \mathrm{C}$ for $30 \mathrm{~min}$. The ALP activity was normalized on the basis of cell numbers from the WST-8 assay.

\subsection{Animal Experiments}

All procedures were approved by the Animal Research Committee of Tohoku University. Nine 10-week-old male Sprague-Dawley rats, weighing 280-300 g, were anesthetized with isoflurane $(1.5-2.0 \%, 4 \mathrm{~L} / \mathrm{min})$. A full-thickness incision was made (proximal to distal) as a 20-mm straight line in the femur area; the ligament of the knee joint was dislocated to expose the femur. The implant cavities were prepared using a pilot drill at 7 and $11 \mathrm{~mm}$ from the distal edge of the femur with irrigation; the implants were then inserted into the bone by manual manipulation. Surgical sites were closed in layers; muscle and skin were sutured separately with resorbable suture thread. Experimental rats were sacrificed after healing periods of 2, 4, and 8 weeks; the femurs within the implants were then harvested to enable evaluation of the degree of osseointegration.

\section{Push-in Test}

Push-in tests were performed to evaluate the level of osseointegration, as reported by Ogawa et al. [15]. The harvested femurs containing the implants were immediately embedded in autopolymerizing resin (FIXPEED, GC, Tokyo, Japan). Push-in tests were performed on a universal testing 
machine (EZ-L-500N, Shimadzu Co., Kyoto, Japan); the resin block was located using a three-dimensional adjustable table to allow vertical loading of the implant. A loading rate of $1 \mathrm{~mm} / \mathrm{min}$ was selected and the push-in test values were defined as the breakpoint load at the implant-tissue interface.

\subsection{Statistical Analysis}

Six samples $(n=6)$ were used to assess the $\mathrm{H}_{2} \mathrm{O}$ contact angle and three were used for the cell culture studies; differences in surface modification were examined by the non-parametric Kruskal-Wallis test. If necessary, the post-hoc Bonferroni test was used; $p<0.05$ was considered to be significant. Five samples were used for surface roughness. The ANOVA test was used. If necessary, the post-hoc Bonferroni test was used; $p<0.05$ was considered to be significant. Five samples were used for the push-in test. The two-way ANOVA test was used to examine the effect of the length of the healing period and the difference in implant surfaces. Where indicated, the Bonferroni was used to confirm the ANOVA results. At each healing period, the Mann-Whitney $U$ test was used to analyze the effect of the differences in surface modifications; $p<0.05$ was considered to be significant. Statistical analysis was performed with SPSS 24 (IBM; Armonk, NY, USA).

\section{Results}

\subsection{Surface Characteristics}

\subsubsection{Surface Morphology}

Scanning electron microscopy observation and EDX examination were performed to detect the surface micromorphology and elemental composition. Figure 2 shows the SEM micrographs and EDX spectra of the substrate surface before the experiments. The SEM micrographs of Ti showed polishing marks on the surface of the substrate metal (Figure 2A,D), while the surfaces of CTO 700 and 800 were covered by $\mathrm{CaTiO}_{3}$ film. The $\mathrm{CaTiO}_{3}$ film surface showed a cauliflower-like texture; in particular, the surface of CTO 800 exhibited nanoparticle structures (Figure 2B,C,E,F). The EDX spectra of the CTO 700 and CTO 800 mainly included characteristic Ti metal, O, and Ca peaks (Figure 2G-I).

\section{$\begin{array}{lll}\mathrm{Ti} & \text { CTO } 700 & \text { CTO } 800\end{array}$}
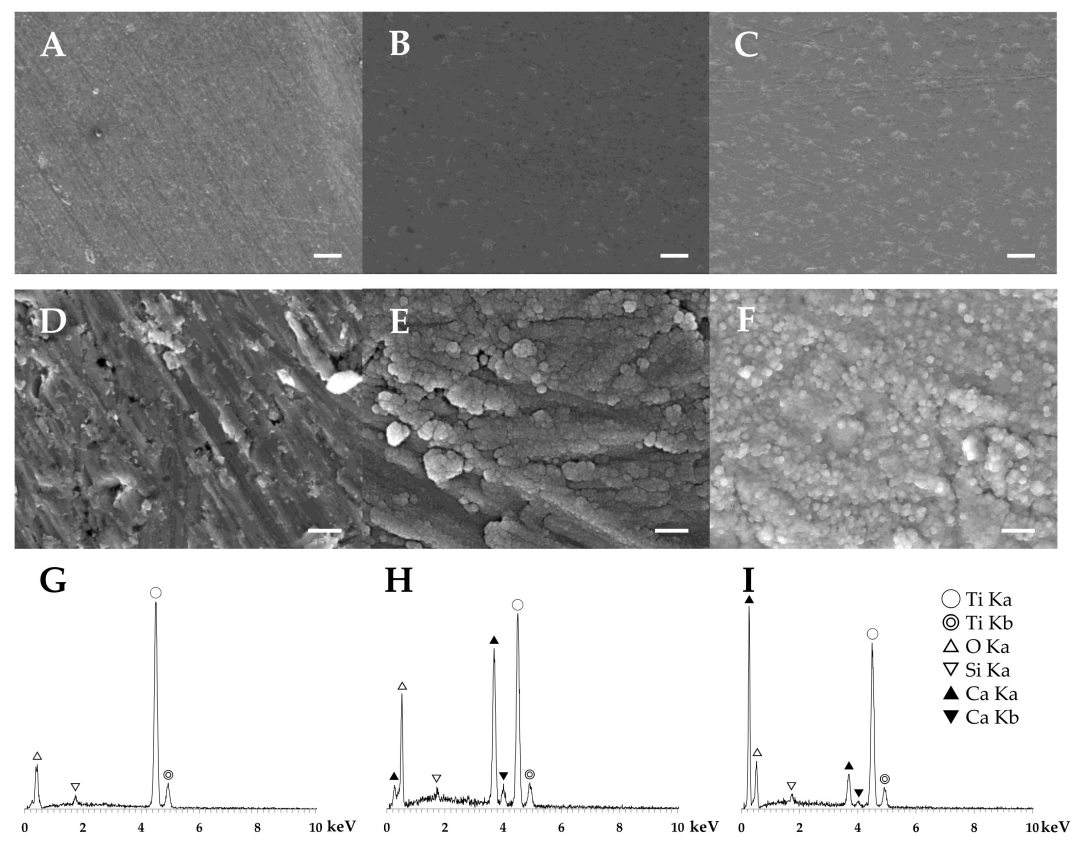

Figure 2. Scanning electron micrographs and energy-dispersive $X$-ray (EDX) spectra of specimen surfaces. (A,D,G) Ti; (B,E,H) CTO 700; and (C,F,I) CTO 800. EDX spectra (G-I) indicate EDX spot elemental analysis sites shown in (D-F), respectively. Bars $=100 \mu \mathrm{m}(\mathbf{A}-\mathbf{C}) ; 1 \mu \mathrm{m}(\mathbf{D}-\mathbf{F})$. 


\subsubsection{Surface Roughness Measurement}

Three-dimensional surface images were obtained, and surface roughness ( $\mathrm{Sa}, \mathrm{Sp}, \mathrm{Sv}$ and $\mathrm{Sz}$ values) was measured by a three-dimensional non-contact surface roughness tester (Figure 3 and Table 1). Three-dimensional surface images revealed that the surface morphology of CTO 700 was affected by a morphological feature of the substrate metal (Figure 3B), while the surface of CTO 800 was completely covered with $\mathrm{CaTiO}_{3}$ film and did not exhibit polishing marks on the surface. The calculated 3D roughness parameters ( $\mathrm{Sa}, \mathrm{Sq}$ and $\mathrm{Sz}$ ) of CTO 800 showed significant differences for that of Ti, except Sv. The Bonferroni test showed significant differences between CTO 700 and CTO 800 in Sa (Table 1).
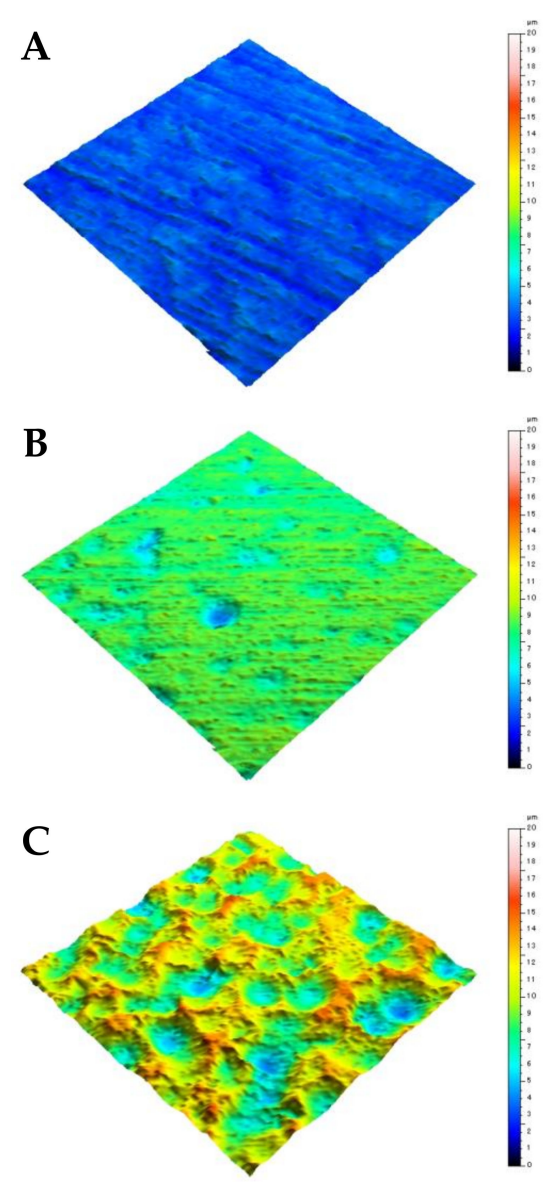

Figure 3. Three-dimensional images of specimen surfaces. (A) Ti. (B) CTO 700. (C) CTO 800.

Table 1. Surface roughness of specimens measured by a three-dimensional non-contact surface roughness tester. Results are mean \pm standard deviation. ${ }^{*} p<0.05, \mathrm{v}$. Ti and CTO 800. ${ }^{\dagger} p<0.05, \mathrm{v}$. CTO 700 and CTO 800.

\begin{tabular}{ccccc}
\hline & & & & $(\boldsymbol{\mu m})$ \\
\hline Substrates & Sa & Sp & Sv & Sz \\
\hline $\mathrm{Ti}$ & $0.49 \pm 0.01$ & $3.55 \pm 0.71$ & $3.73 \pm 1.21$ & $7.19 \pm 1.24$ \\
\hline CTO 700 & $0.62 \pm 0.08$ & $4.14 \pm 0.40$ & $5.58 \pm 1.13$ & $9.71 \pm 0.98$ \\
\hline CTO 800 & $0.87 \pm 0.15^{*, \dagger}$ & $5.39 \pm 1.35^{*}$ & $6.25 \pm 1.23$ & $11.64 \pm 0.98^{*}$ \\
\hline
\end{tabular}

\subsubsection{Hydrophilicity Measurement}

The contact angles on the surfaces of CTO 700 and СTO 800 were $68.7 \%$ and $94.6 \%$ lower than that of Ti, respectively. The contact angle of CTO 800 was significantly lower than that of Ti (Kruskal-Wallis 
test, $p=0.005$ ) (Figure $4 \mathrm{~A}$ ). Figure $4 \mathrm{~B}-\mathrm{D}$ shows representative photographic images at $10 \mathrm{~s}$ after dropping $1 \mu \mathrm{L} \mathrm{H}_{2} \mathrm{O}$ onto each surface.

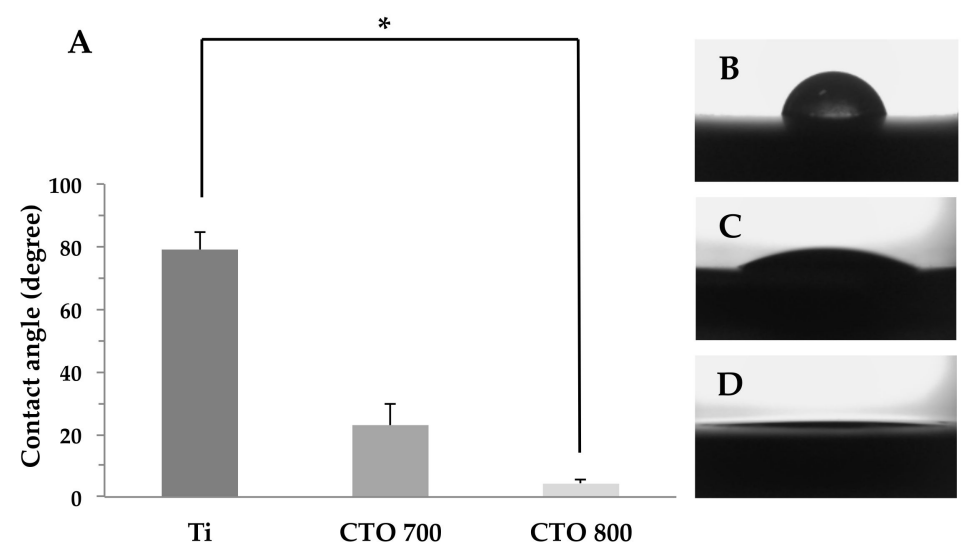

Figure 4. Hydrophilicity of Ti, CTO 700, and CTO 800. (A) Mean contact angle of $1 \mu \mathrm{L} \mathrm{H}_{2} \mathrm{O}$ onto the substrate surface. Data are mean \pm standard deviation. (B-D) typical photographic images of $\mathrm{H}_{2} \mathrm{O}$ droplets pipetted onto the specimen. (B): Ti; (C): CTO 700; (D): CTO 800.

\subsection{Cell Activities}

\subsubsection{Cell Proliferation Assay}

Figure 5A shows ST-2 cell proliferation onto Ti, CTO 700, and CTO 800 disks in ultra-low attachment surface plates. Following $3 \mathrm{~h}$ cultured, the supernatant was removed and exchanged with fresh medium. The Kruskal-Wallis test revealed that there were no significant differences in substrate materials throughout the experiments.

A

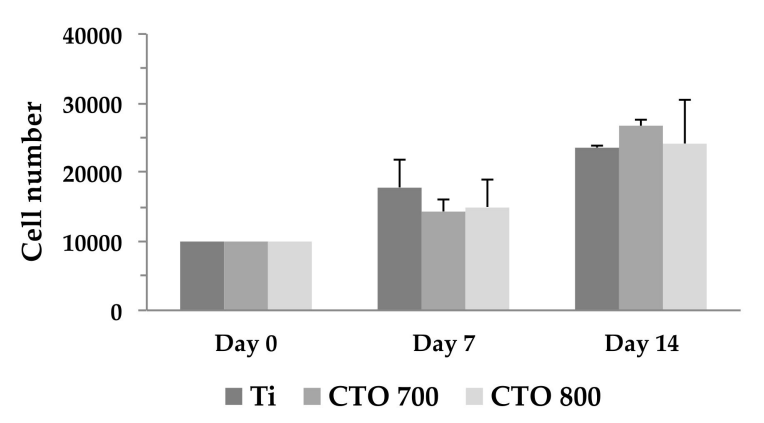

B

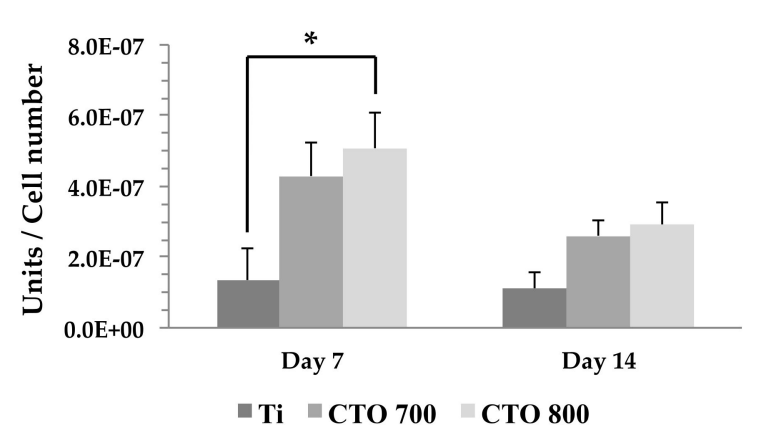

Figure 5. (A) Cell proliferation assay; and (B) alkaline phosphatase activity. Data are mean \pm standard deviation $(n=5)$. 


\subsubsection{Alkaline Phosphatase (ALP) Activity Measurement}

Figure 5B shows the influences of Ti, CTO 700, and CTO 800 specimens on the ALP enzymatic activity of ST- 2 cells. The ALP activity was normalized on the basis of cell numbers from the WST-8 assay. The ALP activities of CTO 700 and CTO 800 were 3.1, 3.8-fold at Day 7, and 2.3, 2.6-fold at Day 14 , higher than that of Ti, respectively. Especially, the Bonferroni test showed significant differences between Ti and CTO 800 on Day $7(p=0.023)$.

\subsection{Push-in Test}

To identify specific advantages of CTO 800 surfaces over Ti, the push-in test was performed (Figure 6). The biomechanical strength of bone-implant integration was higher for CTO 800 surfaces than that for Ti surfaces at healing period of 2 weeks. The difference was substantial, as high as $80 \%$ $(p=0.017)$. However, during the tested healing time from 4 to 8 weeks, there were no differences in biomechanical strength. The Ti surfaces resulted in a significant increase in the push-in test value throughout the tested healing time from 2-8 weeks. The difference was as substantial as 1.7-5.1-fold. The CTO 800 was significantly increased between week 2 and $8(p<0.05)$. These results indicated that CTO 800 surface accelerated the establishment of biomechanical integration between bone and implants and also increased its strength during the periods.

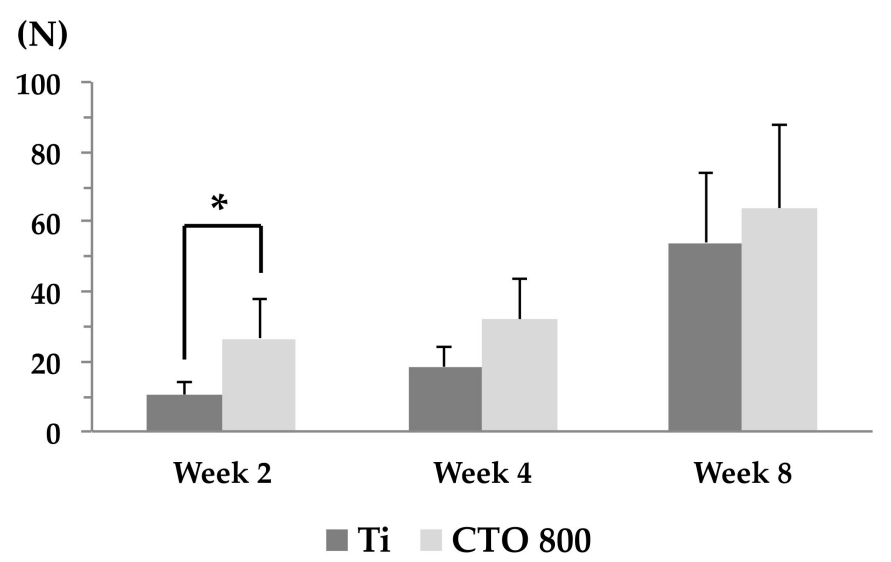

Figure 6. Push-in test values for Ti and CTO 800. Data are mean \pm standard deviation $(n=5)$.

\section{Discussion}

The results of this study showed that $\mathrm{CTO} 800, \mathrm{a} \mathrm{CaTiO}_{3}$ film prepared with a heating temperature of $800{ }^{\circ} \mathrm{C}$, had a highly hydrophilic surface. The ST-2 cells cultured on substrates and CTO 800 exhibited increased cell differentiation, represented by ALP activity, compared with that of Ti and CTO 700. The CTO 800 showed a push-in test value, which indicates the degree of osseointegration, that was significantly higher than the corresponding value for non-coated Ti.

The sessile drop method is commonly used because it easily measures the wettability of implant surfaces. The surface wettability of a biomaterial has been reflected by its topography, surface energy, and surface charge. Hydrophilic surfaces have been reported to accelerate the initial interactions between the surface and the wetting liquid, which is important for wound healing and osseointegration [16]. In this study, surface topographies were determined by both SEM observation and EDX examination; three-dimensional surface images were obtained and surface roughness was measured by a three-dimensional non-contact tester. Albrektsson and Wennerberg [17] classified implant surface into four categories and reported that a moderately rough surface (surface roughness, $\mathrm{Sa}=1-2 \mu \mathrm{m}$ ) might have advantages over other surfaces. Andrukhov [18] reported that a moderately rough surface $(\mathrm{Sa}=1-2 \mu \mathrm{m})$ had a considerable impact on osteoblast differentiation. Furthermore, hybrid micro/nanostructure implant surfaces have been reported to affect osseointegration through managing cell behaviors; micro-nano hybrid structure surfaces increased 
the wettability of such implants [19-21]. In this study, the Sa values for cpTi, CTO 700, and CTO 800 were relatively smoother than those of the prior reports $(0.49 \mu \mathrm{m}, 0.62 \mu \mathrm{m}$, and $0.87 \mu \mathrm{m}$, respectively). However, there were significant differences of Sa between Ti and CTO 800, CTO 700, and CTO 800. In addition, the surface morphology of CTO differed depending on the heating temperature; CTO 800 showed a cauliflower-like texture comprising nanoparticle structures (Figure 2F). This unique surface morphology might affect wettability and lead to accelerated cell differentiation; however, it did not impact proliferation. Most studies have reported that hydrophilic surfaces have the potential to enhance the early stages of cell adhesion, proliferation, differentiation, and bone mineralization compared to hydrophobic surfaces [22,23]. On the other hand, opposite results have been found in studies using different surface energy which cause by UV exposure times, and it is possible that extremely high surface energies promote cell adhesion but suppress the spreading and differentiation of cells. The cell numbers on superhydrophilic surface were lower than those on hydrophobic surfaces materials for $24 \mathrm{~h}$ incubation; however, the ALP activity of superhydrophilic surface was significantly increased compared to the others [24-26]. Osteoblast differentiation can be characterized in three stages: cell proliferation, matrix maturation, and matrix mineralization. The matrix maturation phase is characterized by maximal expression of ALP, an outer cytoplasmic membrane-localized enzyme for phosphate ester hydrolysis. Therefore, ALP is one of the most commonly used markers for osteoblastic cell differentiation at an early stage. Alkaline phosphatase activity is upregulation after proliferation begins to decline and genes for proteins such as osteocalcin and osteopontin are expressed, finally, mineralization is completed [27-29]. In this study, the cell might be proliferated to a confluent state within 7-14 day observation periods. As expected, the high ALP expression of CTO 700 and CTO 800 was observed at day 7 and followed by downregulation of ALP expression at day 14. On the other hand, the level of ALP activity of Ti was not changed dramatically. The ST-2 cell differentiation on CTO 700 and CTO 800 at day 14 might be the early stage in matrix mineralization. These results suggest that titanate surface might not increase cell proliferation, but affect the osteoblastic cell differentiation, and the effect of surface characterization could not be separated from surface topography, chemical composition, and osteoconductivity.

A push-in test is a widely accepted model for evaluation of the level of osseointegration [15]. In this study, the push-in test value of CTO 800 in Week 2 was significantly higher than that of Ti; however, there were no significant differences in Weeks 4 and 8 . The surface of $\mathrm{CaTiO}_{3}$ reportedly releases calcium ions in FBS; in addition, phosphate is strongly adsorbed in experiments with $\mathrm{CaTiO}_{3}$ powder $[6,11,13]$. Moreover, $\mathrm{HA}$ and/or OCP formation has been identified on the surface of $\mathrm{CaTiO}_{3}$ films after immersion in Hank's solution, particularly, OCP formation has been detected only the CTO 800 surface, not CTO 700. A OCP formation was detected by X-ray diffraction, after as few as $6 \mathrm{~h}$ of immersion; notably, HA formation occurred after three days [13], which is consistent with observations that OCP is formed prior to $\mathrm{HA}[30,31]$. The OCP has the potential to promote osteoblastic differentiation toward osteocytes in vitro [32]. Thus, these phenomena may promote apatite nucleation on the surface in the early stages of wound healing and may lead to earlier osseointegration after implantation into the femur.

\section{Conclusions}

$\mathrm{CaTiO}_{3}$ directly coated on Ti by MOCVD may accelerate the process of osseointegration. Moreover, $\mathrm{CaTiO}_{3}$ coating could be a suitable candidate to serve as a biocompatible biomaterial for medical applications, particularly those involving dental implants.

Author Contributions: Conceptualization, N.S. and K.S.; Methodology, N.S., O.S. and T.A.; Validation, T.O. and T.G.; Formal analysis, N.S.; Investigation, N.S., R.I.-U. and K.T.; Resources, T.G.; Data curation, N.S., R.I.-U. and K.T.; Writing — original draft preparation, N.S.

Funding: This work was supported in part by a Grant-in-Aid for Scientific Research (No. 25861822) and Research and Education Funding for Inter-University Research Project (Highly-functional Interface Science: Innovation 
of Biomaterials with Highly-Functional Interface to Host and Parasite) from the Ministry of Education, Culture, Sports, Science and Technology of Japan.

Conflicts of Interest: The authors declare no conflict of interest.

\section{References}

1. Dumbleton, J.; Manley, M.T. Hydroxyapatite-coated prostheses in total hip and knee arthroplasty. J. Bone. Jt. Surq. A 2004, 86, 2526-2540. [CrossRef]

2. Surmenev, R.A.; Surmeneva, M.A.; Ivanova, A.A. Significance of calcium phosphate coatings for the enhancement of new bone osteogenesis-A review. Acta Biomater. 2014, 10, 557-579. [CrossRef]

3. Rahbek, O.; Overgaard, S.; Jensen, T.B.; Bendix, K.; Soballe, K. Sealing effect of hydroxyapatite coating: A 12-month study in canines. Acta Orthop. Scand. 2000, 71, 563-573. [CrossRef]

4. Cunningham, B.W.; Hu, N.; Zorn, C.M.; McAfee, P.C. Bioactive titanium calcium phosphate coating for disc arthroplasty: Analysis of 58 vertebral end plates after 6 to 12-month implantation. Spine. J. 2009, 9, 836-845. [CrossRef]

5. Massaro, C.; Baker, M.A.; Cosentino, F.; Ramires, P.A.; Klose, S.; Milella, E. Surface and biological evaluation of hydroxyapatite-based coatings on titanium deposited by different techniques. J. Biomed. Mater. Res. 2001, 58, 651-657. [CrossRef]

6. Lee, I.S.; Kim, D.H.; Kim, H.E.; Jung, Y.C.; Han, C.H. Biological performance of calcium phosphate films formed on commercially pure Ti by electron-beam evaporation. Biomaterials 2002, 23, 609-615. [CrossRef]

7. Yu, L.G.; Khor, K.A.; Li, H.; Cheang, P. Effect of spark plasma sintering on the microstructure and in vitro behavior of plasma sprayed HA coatings. Biomaterials 2003, 24, 2695-2705. [CrossRef]

8. Ohtsu, N.; Sato, K.; Saito, K.; Asami, K.; Hanawa, T. Calcium phosphates formation on $\mathrm{CaTiO}_{3} \mathrm{Coated}$ titanium. J. Mater. Sci. Mater. Med. 2007, 18, 1009-1016. [CrossRef]

9. Holliday, S.; Stanishevsky, A. Crystallization of $\mathrm{CaTiO}_{3}$ by sol-gel synthesis and rapid thermal processing. Surf. Coat. Technol. 2004, 188-189, 741-744. [CrossRef]

10. Webster, T.J.; Ergun, C.; Doremus, R.H.; Lanford, W.A. Increased osteoblast adhesion on titanium-coated hydroxylapatite that forms $\mathrm{CaTiO}_{3}$. J. Biomed. Mater. Res. Part A 2003, 67, 975-980. [CrossRef]

11. Coreño, J.; Coreño, O. Evaluation of calcium titanate as apatite growth promoter. J. Biomed. Mater. Res. Part A 2005, 75, 478-484. [CrossRef] [PubMed]

12. Ohtsu, N.; Sato, K.; Saito, K.; Hanawa, T.; Asami, K. Evaluation of degradability of $\mathrm{CaTiO}_{3}$ thin films in simulated body fluids. Mater. Trans. 2004, 45, 1778-1781. [CrossRef]

13. Sato, M.; Tu, R.; Goto, T.; Ueda, K.; Narushima, T. Hydroxyapatite formation on $\mathrm{CaTiO}_{3}$ film prepared by metal-organic chemical vapor deposition. Mater. Trans. 2007, 48, 1505-1510. [CrossRef]

14. Sato, M.; Tu, R.; Goto, T. Preparation conditions of $\mathrm{CaTiO}_{3}$ film by metal-organic chemical vapor deposition. Mater. Trans. 2006, 47, 1386-1390. [CrossRef]

15. Ogawa, T.; Ozawa, S.; Shih, J.H.; Ryu, K.H.; Sukotjo, C.; Yang, J.M.; Nishimura, I. Biomechanical evaluation of osseous implants having different surface topographies in rats. J. Dent. Res. 2000, 79, 1857-1863. [CrossRef]

16. Rupp, F.; Gittens, R.A.; Scheideler, L.; Scheideler, L.; Marmur, A.; Boyan, B.D.; Schwartz, Z.; Geis-Gerstorfer, J. A review on the wettability of dental implant surfaces I: Theoretical and experimental aspects. Acta Biomater. 2014, 10, 2894-2906. [CrossRef] [PubMed]

17. Wennerberg, A.; Albrektsson, T. Effects of titanium surface topography on bone integration: A systematic review. Clin. Oral. Implants. Res. 2009, 20, 172-184. [CrossRef] [PubMed]

18. Andrukhov, O.; Huber, R.; Shi, B.; Berner, S.; Rausch-Fan, X.; Moritz, A.; Spencer, N.D.; Schedle, A. Proliferation, behavior, and differentiation of osteoblasts on surfaces of different microroughness. Dent. Mater. 2016, 32, 1374-1384. [CrossRef]

19. Cheng, B.; Niu, Q.; Cui, Y.; Jiang, W.; Zhao, Y.; Kong, L. Effects of different hierarchical hybrid micro/nanostructure surfaces on implant osseointegration. Clin. Implant. Dent. Relat. Res. 2017, 19, 539-548. [CrossRef]

20. Kim, B.S.; Shin, S.; Shin, S.J.; Kim, K.M.; Cho, H.H. Micro-nano hybrid structures with manipulated wettability using a two-step silicon etching on a large area. Nanoscale. Res. Lett. 2011, 6, 1-10. [CrossRef]

21. Kim, D.S.; Lee, B.K.; Yeo, J.; Choi, M.J.; Yang, W.; Kwon, T.H. Fabrication of PDMS micro/nano hybrid surface for increasing hydrophobicity. Microelectron. Eng. 2009, 86, 1375-1378. [CrossRef] 
22. Eriksson, C.; Nygren, H.; Ohlson, K. Implantation of hydrophilic and hydrophobic titanium discs in rat tibia: Cellular reactions on the surfaces during the first 3 weeks in bone. Biomaterals 2004, 25, 4759-4766. [CrossRef] [PubMed]

23. Aita, H.; Att, W.; Ueno, T.; Yamada, M.; Hori, N.; Iwasa, F.; Tsukimura, N.; Ogawa, T. Ultraviolet light-mediated photofunctionalization of titanium to promote human mesenchymal stem cell migration, attachment, proliferation and differentiation. Acta Biomater. 2009, 5, 3247-3257. [CrossRef] [PubMed]

24. Kennedy, S.B.; Washburn, N.R.; Simon, C.G., Jr.; Amis, E.J. Combinatorial screen of the effect of surface energy on fibronectin-mediated osteoblast adhesion, spreading and proliferation. Biomaterials 2006, 27, 3817-3824. [CrossRef] [PubMed]

25. Qiu, Q.; Sayer, M.; Kawaja, M.; Shen, X.; Davies, J.E. Attachment, morphology, and protein expression of rat marrow stromal cells cultured on charged substrate surfaces. J. Biomed. Mater. Res. 1998, 42, 117-127. [CrossRef]

26. Zhao, G.; Schwartz, Z.; Wieland, M.; Rupp, F.; Geis-Gerstorfer, J.; Cochran, D.L.; Boyan, B.D. High surface energy enhances cell response to titanium substrate microstructure. J. Biomed. Mater. Res. 2005, 74, 49-58. [CrossRef] [PubMed]

27. Dworetzky, S.I.; Fey, E.G.; Penman, S.; Lian, J.B.; Stein, J.L.; Stein, G.S. Progressive changes in the protein composition of the nuclear matrix during rat osteoblast differentiation. Proc. Natl. Acad. Sci. USA 1990, 87, 4605-4609. [CrossRef]

28. Bellows, C.G.; Heersche, J.N.; Aubin, J.E. Inorganic phosphate added exogenously or released from beta-glycerophosphate initiates mineralization of osteoid nodules in vitro. Bone. Miner. 1992, 17, 15-29. [CrossRef]

29. Lian, J.B.; Stein, G.S. Concepts of osteoblast growth and differentiation: Basis for modulation of bone cell development and tissue formation. Crit. Rev. Oral. Biol. Med. 1992, 3, 269-305. [CrossRef]

30. Brown, W.E.; Smith, J.P.; Lehr, J.R.; Frazier, A.W. Crystallographic and chemical relations between octacalcium phosphate and hydroxyapatite. Nature 1962, 196, 1050-1055. [CrossRef]

31. Suzuki, O.; Nakamura, M.; Miyasaka, Y.; Kagayama, M.; Sakurai, M. Bone formation on synthetic precursors of hydroxyapatite. Tohoku J. Exp. Med. 1991, 164, 37-50. [CrossRef] [PubMed]

32. Sai, Y.; Shiwaku, Y.; Anada, T.; Tsuchiya, K.; Takahashi, T.; Suzuki, O. Capacity of octacalcium phosphate to promote osteoblastic differentiation toward osteocytes in vitro. Acta Biomater. 2018, 69, 362-371. [CrossRef] [PubMed]

(C) 2019 by the authors. Licensee MDPI, Basel, Switzerland. This article is an open access article distributed under the terms and conditions of the Creative Commons Attribution (CC BY) license (http:/ / creativecommons.org/licenses/by/4.0/). 